\title{
USO DO 1-METILCICLOPROPENO NO CONTROLE DA MATURAÇÃO DE MAÇÃS CV. 'ROYAL GALA' ${ }^{\prime}$
}

\author{
ADRIANA REGINA CORRENT², AGUINALDO PARUSSOLO², CÉSAR LUIZ GIRARDI ${ }^{3}$, \\ CESAR VALMOR ROMBALDI ${ }^{4}$
}

\begin{abstract}
RESUMO - Avaliou-se o efeito do 1-metilciclopropeno (1-MCP) no controle da maturação de maçãs 'Royal Gala'. As frutas foram colhidas em dois estádios de maturação caracterizados como: estádio de maturação 1, com frutas apresentando firmeza de polpa de 82,14 N, acidez total titulável de $0,36 \%$ de ácido málico, teor de sólidos solúveis totais de $14,10^{\circ}$ Brix e produção de etileno de $2,00 \mathrm{~nL} \mathrm{~g}^{-1} \cdot \mathrm{h}^{-1}$, e estádio de maturação 2 , com maçãs apresentando firmeza de polpa de 79,96 N, acidez total titulável de $0,33 \%$ de ácido málico, teor de sólidos solúveis totais de $13,74{ }^{\circ}$ Brix e produção de etileno de $17,11 \mathrm{~nL} \cdot \mathrm{g}^{-1} \cdot \mathrm{h}^{-1}$. Foram testadas quatro concentrações de 1-MCP: $0 ; 312 ; 625$ e $1250 \mathrm{~nL} \cdot \mathrm{L}^{-1}$. A aplicação foi efetuada durante 48 horas, à temperatura de $20 \pm 2{ }^{\circ} \mathrm{C}$, em câmaras com capacidade para $300 \mathrm{~L}$. Após a aplicação, as frutas foram armazenadas a $20 \pm 2{ }^{\circ} \mathrm{C}$, por 60 dias. A cada 10 dias, avaliaram-se a firmeza de polpa, a acidez total titulável, o teor de sólidos solúveis totais e a produção de etileno. O 1-MCP reduziu a produção de etileno nas maçãs e retardou a ocorrência do pico climatérico, independentemente do estádio de maturação e da concentração do produto. Em conseqüência, preservou maiores valores de firmeza de polpa e acidez total titulável.
\end{abstract}

Termos de indexação: firmeza de polpa, etileno, armazenagem

\section{1-METHYLCYCLOPROPENE IN THE CONTROL OF THE RIPENING AND IN THE MAINTENANCE OF QUALITY OF 'ROYAL GALA' APPLES}

\begin{abstract}
In the present work were evaluated the effects of 1-MCP on 'Royal Gala' apples ripening. The apples were harvested at two ripeness stages: Ripeness stage at harvest one apples were with $82,4 \mathrm{~N}$ flesh firmness, $0,36 \%$ malic acid and $14,10^{\circ}$ Brix. Ethylene prodution of these apples was about $2,0 \mathrm{~nL} \cdot \mathrm{g}^{-1} \cdot \mathrm{h}^{-1}$. Apples of ripeness stage 2 produced about $17,0 \mathrm{~nL} \cdot \mathrm{g}^{-1} \cdot \mathrm{h}^{-1}$ ethylene and had flesh firmness values $79,96 \mathrm{~N}, 0,33 \%$ malic acid and $13,74^{\circ}$ Brix. The apples were treated with 1-methylcyclopropene (1-MCP) using three concentrations and one control, 0, 325, 625 and $1250 \mathrm{~nL} . \mathrm{L}^{-}$ ${ }^{1}$ which were applied during 48 hours at temperature of $20 \pm 2{ }^{\circ} \mathrm{C}$. After this time the fruits were stored during 60 days at the same temperature. Flesh firmness, titratable acidity, soluble solids and ethylene production were evaluated at every 10 days. All concentrations of the 1-MCP product have reduced the fruit's ethylene production and delayed the occurrence of the climacteric peak independently of the ripening stage. The treatments with 1-MCP also gave the bigger values of pulp firmness and titratable acidity.
\end{abstract}

Index terms: pulp firmness, ethylene, storage

\section{INTRODUÇÃO}

Embora o etileno atue em praticamente todos os estádios do crescimento e de desenvolvimento das plantas, é conhecido, sobretudo, como o hormônio da maturação de frutas climatéricas e da senescência de flores (Abeles et al., 1992). De maneira geral, as estratégias empregadas para o controle da maturação e, por conseqüência, do aumento da conservabilidade de frutas climatéricas baseiam-se no controle da produção e/ou da ação do etileno. Por exemplo, a aplicação de aminoetoxivinilglicina (AVG) na pré-colheita, a conservação com baixas concentrações de $\mathrm{O}_{2}$ e elevadas concentrações de $\mathrm{CO}_{2}$ na póscolheita reduzem as taxas de produção do etileno. Como resultado, dependendo da espécie e da cultivar, retarda-se o amadurecimento e aumenta-se a vida útil das frutas após a colheita. Todas essas ferramentas podem ser empregadas concomitantemente, ou seja, AVG na pré-colheita e elevado $\mathrm{CO}_{2}$ e reduzido $\mathrm{O}_{2}$ na pós-colheita.

Sisler et al. (1996) sintetizaram o 1-MCP e observaram que ele atua como potente inibidor da ação do etileno. Vários trabalhos, utilizando esse produto, demonstraram seu efeito positivo na melhoria do potencial de conservação de frutas (Golding et al., 1998; Abdi et al., 1998; Porat el al., 1999; Fan et al., 1999; Watkins et al., 2000; Zanella, 2001; Mir et al., 2001) e flores (Sisler \& Serek, 1997). Porém, em alguns casos, observou-se que, dependendo da espécie, cultivar e condições edafoclimáticas, os resultados são contraditórios. Por exemplo, de maneira geral, em ameixas, os efeitos são positivos, prolongando a vida de prateleira das frutas, enquanto, em algumas cultivares de pêssegos, o efeito é negativo, desencadeando a ocorrência de distúrbios fisiológicos. Também, para cultivares produzidas em regiões edafoclimáticas distintas, os resultados são diferentes (Watkins, 2002). À semelhança do que ocorre com prunóides, em maçãs, os resultados também apresentam variabilidade entre as cultivares. Porém, geralmente, há maior efeito do 1-MCP em cultivares com maior produção e sensibilidade ao etileno. Como maçãs do grupo Gala caracterizam-se por elevada produção de etileno, acredita-se que a aplicação do 1-MCP possa reduzir a velocidade da maturação e prolongar a vida útil desta cultivar, reduzindo as perdas de firmeza de polpa e mantendo elevados teores de sólidos solúveis totais e acidez total titulável. Com isso, podese prolongar o período de conservação/comercialização sem utilizar a refrigeração.

Em torno de $15 \%$ da produção nacional de maçãs é comercializada imediatamente após a colheita, sem armazenamento em câmaras frigoríficas. Essas frutas têm tido destaque, pois caracterizamse por excelente crocância, suculência, firmeza de polpa e acidez. Com o avanço do período de comercialização, observa-se o amarelecimento da epiderme e a perda da firmeza de polpa e de acidez, depreciando a qualidade das frutas.

A velocidade e a intensidade dessas alterações estão diretamente ligadas ao metabolismo do etileno. Assim, em alguns casos, a firmeza de polpa apresenta-se como etileno-dependente e em outros etileno-independente. Isso também é citado para a bioconversão de açúcares e de ácidos orgânicos (Ayub et al., 1996; Atkinson et al., 1998; Pech, 2002).

Nesse contexto, o objetivo deste trabalho foi avaliar o tempo de conservação e a qualidade de frutos de maçã 'Royal Gala' tratados com 1-MCP e armazenadas à temperatura de $20 \pm 2{ }^{\circ} \mathrm{C}$.

\footnotetext{
(Trabalho 168/2003). Recebido: 07/11/2003. Aceito para publição: 09/06/2005.

${ }^{2}$ Eng. Agr. Doutoranda do Programa de Pós-Graduação em Fitotecnia, Faculdade de Agronomia, Dep. de Horticultura, Universidade Federal do Rio Grande do Sul. Caixa Postal 15100, CEP 91-501-970, Porto Alegre-RS, e-mail- ACORRENT@HOTMAIL.COM, Bolsista CNPq

${ }^{2}$ Químico Industrial MSc. Ministério da Agricultura, Pecuária e Abastecimento, Porto Alegre-RS. aguipar@agricultura.gov.br.

${ }^{3}$ Pesquisador II MSc. Embrapa Uva e Vinho, Bento Gonçalves-RS. girardi@cnpuv.embrapa.br.

${ }^{4}$ Professor do Departamento de Ciência e Tecnologia Agroindustrial, UFPel. Universidade Federal de Pelotas, Pelotas-RS. cesarvrf@ufpel.tche.br
} 


\section{MATERIAL E MÉTODOS}

As maçãs da cultivar Royal Gala foram colhidas em pomar experimental da Estação Experimental de Vacaria, pertencente à Embrapa Uva e Vinho de Bento Gonçalves. As maçãs foram colhidas em dois estádios de maturação (Fator A), caracterizados como: estádio de maturação 1 e estádio de maturação 2 , colhidas 15 dias após a primeira colheita. As frutas colhidas no estádio de maturação 1 apresentavam firmeza de polpa de $82,14 \mathrm{~N}$, acidez total titulável de $0,36 \%$ de ácido málico, teor de sólidos solúveis totais de $14,10{ }^{\circ}$ Brix e produção de etileno de $2,00 \mathrm{~nL} \cdot \mathrm{g}^{-1} \cdot \mathrm{h}^{-1}$, enquanto as colhidas no estádio 2 apresentavam firmeza de polpa de $79,96 \mathrm{~N}$, acidez total titulável de $0,33 \%$ de ácido málico, teor de sólidos solúveis totais de $13,74{ }^{\circ}$ Brix e produção de etileno de $17,11 \mathrm{~nL} \cdot \mathrm{g}^{-1} \cdot \mathrm{h}^{-1}$.

Após a colheita, as frutas foram tratadas com os fungicidas Iprodione (150 g. $\left.100 \mathrm{~L}^{-1}\right)$ e Benomil $\left(60 \mathrm{~g} .100 \mathrm{~L}^{-1}\right)$. Em seguida, foram acondicionadas em câmaras com capacidade média de 300 L. Para o tratamento com 1-MCP (Fator B), pesaram-se quantidades do produto comercial em pó suficientes para proporcionar concentrações finais de 312; 625 e 1250 nL.L $\mathrm{L}^{-1}$. O produto comercial foi posto em frascos hermeticamente fechados, onde foi dissolvido numa solução de dodecil sulfato de sódio (SDS) a $0,1 \%$, à temperatura de $50^{\circ} \mathrm{C}$. Prepararam-se 10 $\mathrm{mL}$ de solução em cada frasco. Após dissolvido o produto, os frascos foram levados para as incubadoras e então abertos, permitindo que o produto entrasse em contato com as frutas. As câmaras permaneceram fechadas por 48 horas, à temperatura de $20 \pm 2{ }^{\circ} \mathrm{C}$ e umidade relativa entre 70 a $75 \%$. O tratamento-controle foi mantido nas mesmas condições, porém sem a aplicação de 1-MCP. Após o tratamento, as frutas foram armazenadas a $20 \pm 2{ }^{\circ} \mathrm{C}$, por um período de 60 dias. As frutas foram avaliadas na instalação do experimento e aos $10 ; 20 ; 30 ; 40$; 50 e 60 dias (Fator C). As variáveis analisadas foram:

a) Sólidos solúveis totais (SST): determinados com auxílio de refratômetro portátil digital da marca Atago. Os resultados foram expressos em ${ }^{\circ}$ Brix.

b) Firmeza da polpa (FP): determinada com auxílio de penetrômetro manual, munido de ponteira de $11 \mathrm{~mm}$ de diâmetro, expressando-se os resultados em Newtons. Em cada fruta, foram realizadas 2 leituras em lados opostos, na seção equatorial das maçãs, após a remoção da epiderme.

c) Acidez total titulável (ATT): foi determinada por titulometria de neutralização com $\mathrm{NaOH} 0,1 \mathrm{~N}$, utilizando $10 \mathrm{~mL}$ de suco provenientes de pedaços das 10 maçãs, diluídos em $90 \mathrm{~mL}$ de água destilada, titulandose até $\mathrm{pH} 8,1$, e os resultados expressos em \% de ácido málico.

d) Produção de etileno (PE): foi determinada a partir da coleta de $1 \mathrm{~mL}$ da amostra gasosa resultante da incubação de aproximadamente $1 \mathrm{~kg}$ de frutas em frascos de $5 \mathrm{~L}$, hermeticamente fechados, e mantidos a $20 \pm 2{ }^{\circ} \mathrm{C}$, durante 1 hora. $\mathrm{O}$ etileno produzido foi determinado por cromatografia gasosa em cromatógrafo da marca $\mathrm{CG}^{\circledR}$, Modelo 3537D, coluna de aço inox 1/8" preparada com Porapak ${ }^{\circledR}$ QS $(1,2 \mathrm{~m}$ de comprimento ), e detector de ionização de chama. Os resultados foram expressos em nanolitros de etileno, por hora, por grama de fruto (nL.g$\left.{ }^{1} \cdot h^{-1}\right)$.

O experimento foi conduzido em esquema fatorial $(2 \times 3 \times 7)$ com delineamento inteiramente casualizado, com 3 repetições de 10 frutas cada. Os dados foram submetidos à análise de variância, sendo os efeitos dos tratamentos sobre as variáveis avaliados por regressão. Para a realização das análises, foi utilizado o programa WinStat (Sistema de Análise Estatística para Windows, versão 1.2, 2002).

\section{RESULTADOS E DISCUSSÃO}

A produção de etileno foi significativamente influenciada pela aplicação de 1-MCP, independentemente da concentração e do estádio de maturação. Embora em todos os tratamentos se tenha observado comportamento climatérico, o 1-MCP retardou o início do incremento da produção de etileno (Figura 1A).
As maçãs colhidas no estádio de maturação 1 apresentaram produção inicial de etileno baixa, em média de $2,0 \mathrm{~nL} \cdot \mathrm{g}^{-1} \cdot \mathrm{h}^{-1}$. A partir daí, nos dois primeiros períodos de avaliação, houve aumento significativo da produção de etileno naquelas frutas não-tratadas com 1-MCP, atingindo valores em torno de $40 \mathrm{~nL} \cdot \mathrm{g}^{-1} \cdot \mathrm{h}^{-1}$. Esse comportamento é normal e também foi observado em outros trabalhos (Fan et al., 1999; Argenta et al., 2001), embora os valores sejam distintos. O incremento observado é resultado do estresse e danos causados por ocasião da colheita e pelo próprio processo de maturação. Naquelas maçãs onde houve a aplicação de 1-MCP, em todas as concentrações estudadas, houve significativo retardo do início do pico climatérico, que começou a partir do $20^{\circ}$ dia após a colheita. A partir daí, a produção de etileno aumentou e estabeleceu-se o comportamento climatérico. Lelièvre et al. (1997) demonstraram que, inibindo-se a ação do etileno, também se inibe sua produção. Com maçãs 'Royal Gala' neste experimento, isso ocorreu apenas nos primeiros 20 dias de avaliação. Embora o 1-MCP se ligue de forma irreversível aos sítios de recepção do etileno, o aumento da síntese de receptores pode explicar o incremento de produção e o efeito autocatalítico, após 20 dias de avaliação. Isso é concordante com outros trabalhos que demonstram que a expressão do gene ETR1 aumenta com o amadurecimento (Lelièvre et al., 1997). Por isso, para controlar a ação do etileno, provavelmente, sejam necessárias aplicações sucessivas de 1-MCP, como testado por Mir et al. (2001).

Em frutas colhidas em estádio mais avançado de maturação, caracterizado como maturação comercial, a evolução da produção de etileno foi semelhante àquela observada em frutas colhidas na maturação 1. Ressalta-se, no entanto, que, após a colheita, as frutas em maturação comercial apresentavam uma produção de etileno de $15 \mathrm{a} 17 \mathrm{~nL} \cdot \mathrm{g}^{-1} \cdot \mathrm{h}^{-1}$, enquanto as frutas colhidas no estádio de maturação 1 apresentavam apenas $2,0 \mathrm{~nL} \cdot \mathrm{g}^{-1} \cdot \mathrm{h}^{-1}$. Após a aplicação de 1-MCP, houve significativa redução da produção de etileno, que se estabilizou até o $20^{\circ}$ dia de avaliação. A partir daí, desencadeou-se o climatério (Figura 1A e 1B).

A firmeza de polpa, um dos principais atributos de qualidade de maçãs, também foi significativamente influenciada pela aplicação de 1-MCP. Independentemente da concentração e do estádio de maturação, frutas tratadas com 1-MCP mantiveram a firmeza de polpa superior àquelas não-tratadas, embora tenha havido diminuição da firmeza em todos os tratamentos (Figura 1C e 1D).

Ao se considerarem as recomendações de Mir et al. (2001), que sugerem valores de firmeza de polpa acima de $60 \mathrm{~N}$ para comercialização/consumo de maçãs de qualidade, verifica-se que, para todas as concentrações de 1-MCP testadas e para os dois estádios de maturação, as frutas podem ser conservadas por até 40 dias. Porém, observou-se a ocorrência de murchamento, comprometendo a qualidade das frutas (dados não-apresentados). Além disso, Watkins (2002) cita que o efeito do 1-MCP é inversamente proporcional à temperatura de armazenamento, ou seja, ao se incrementar a temperatura, reduz-se o efeito protetor e, portanto, reduz-se o período seguro de estocagem. Por isso, se as frutas forem armazenadas em condições de temperatura acima de $20^{\circ} \mathrm{C}$, o período seguro de estocagem será menor.

No que concerne à acidez total titulável, observaram-se reduções significativas, seguindo um comportamento linear em todos os tratamentos. Isso é decorrência da evolução da maturação, onde os ácidos orgânicos são metabolizados na via respiratória e convertidos em moléculas não-ácidas (Pech, 2002). Quando se aplicou 1-MCP, os valores de acidez total titulável foram significativamente superiores aos das frutas não-tratadas. O efeito do 1-MCP na promoção de valores mais elevados de acidez total titulável pode ser explicado pela desaceleração do metabolismo, também observado por Zanella (2001) e Fan et al. (1999). Porém, Watkins et al. (2000) e Mir et al. (2001) não observaram efeito do 1-MCP sobre a preservação de valores mais elevados de acidez total titulável, nem no aumento do teor de sólidos solúveis totais.

Os teores de sólidos solúveis totais apresentaram comportamento irregular entre os tratamentos durante o armazenamento. Porém, os valores situavam-se entre 13 e $15^{\circ}$ Brix, considerados 
Maturação 1
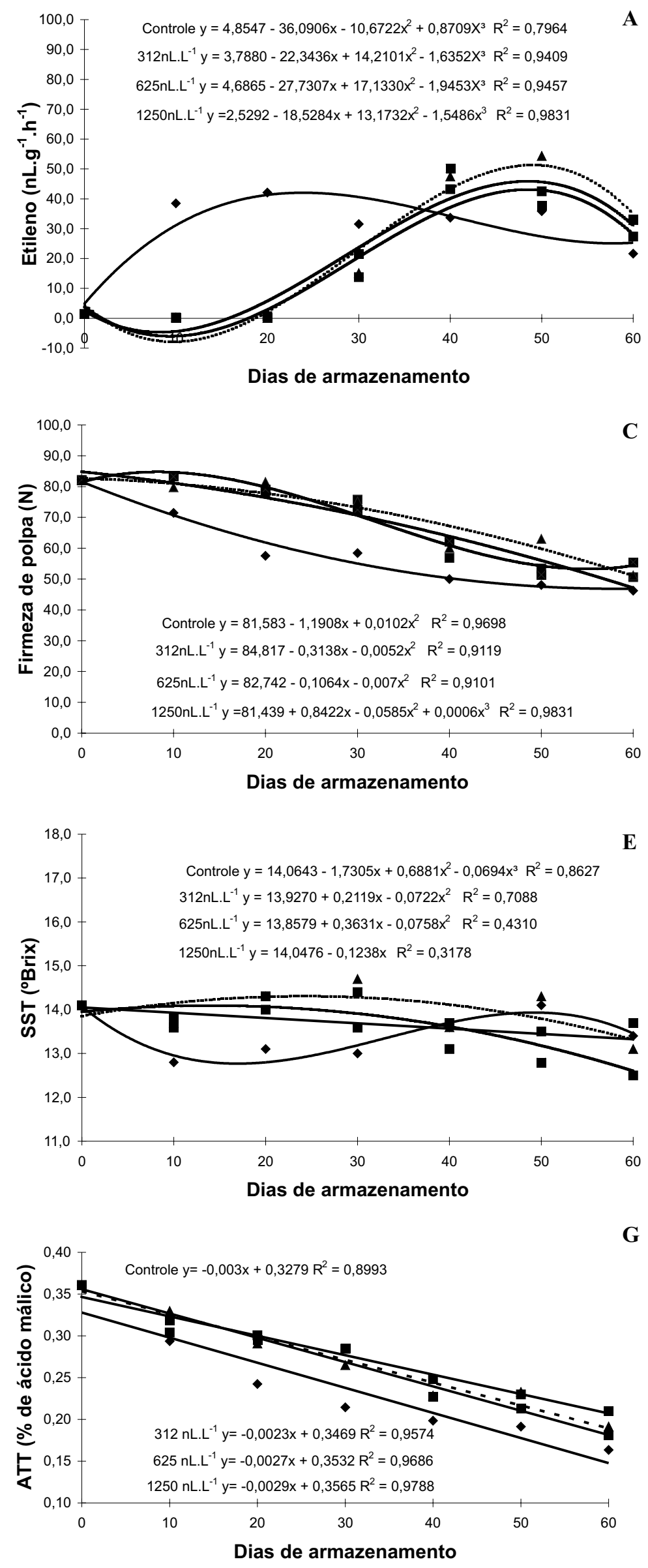

- Controle - 312nL.L-1 \ 625nL.L-1 - 1250nL.L-1 - Controle - $312 \mathrm{~nL} . \mathrm{L}-1 \quad--625 \mathrm{~nL} . \mathrm{L}-1 \quad-1250 \mathrm{~nL} . \mathrm{L}-1$

$\mathbf{E}$
Maturação 2
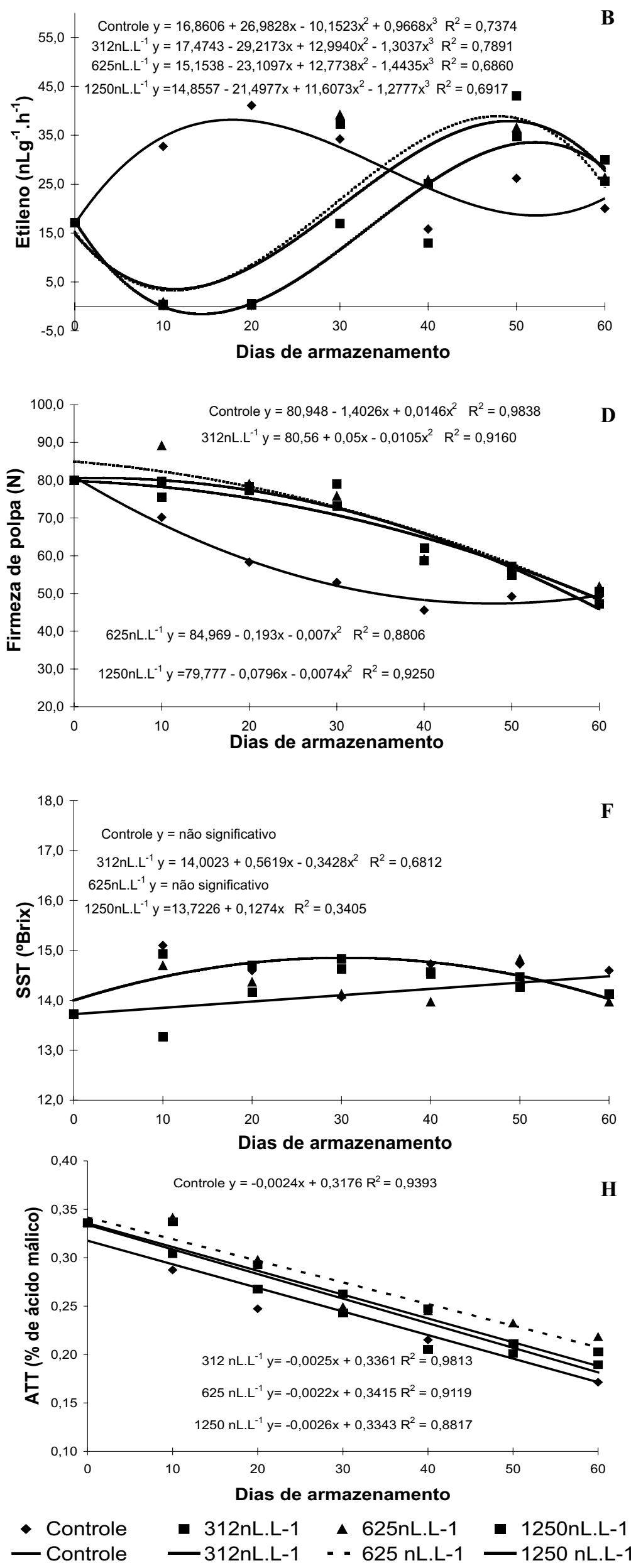

FIGURA 1 - Efeito do 1-MCP na produção de etileno (A, B), firmeza de polpa (C, D), sólidos solúveis totais (E, F) e acidez total titulável (G, H) de maçãs 'Royal Gala' armazenadas a $20 \pm 2^{\circ} \mathrm{C}$, por 60 dias. Bento Gonçalves, 2002. 
excelentes para maçãs 'Royal Gala'. Não houve efeito do 1-MCP sobre as variações do conteúdo de sólidos solúveis totais. Isso também foi observado por Watkins et al. (2001) e Mir et al. (2001).

\section{CONCLUSÕES}

1. 1-MCP reduz as perdas de firmeza de polpa e de acidez total titulável de maçãs 'Royal Gala' quando armazenadas a $20 \pm 2{ }^{\circ} \mathrm{C}$, por até 60 dias.

2. O tratamento com 1-MCP reduz a produção de etileno em maçãs 'Royal Gala' armazenadas a $20 \pm 2{ }^{\circ} \mathrm{C}$.

\section{REFERÊNCIAS}

ABDI, N.; McGLASSON, W. B.; HOLFORD, P.; WILLIANS, M.; MIZRAHI, Y. Responses of climateric and suppressed-climateric plums to treatment with propylene and 1-methylcyclopropene. Postharvest Biology and Technology, Amsterdam, v.14, p.29-39, 1998.

ABELES, F.B.; MORGAN, P.W.; SALTVEIT JR, M.E. Ethylene in plant biology. $2^{\text {nd }}$ ed. San Diego: Academic Press, 1992. v.15.

ARGENTA, L.C.; MATTHEIS, J.; FAN, X. Retardamento da maturação de maçãs 'Fuji' pelo tratamento com 1-MCP e manejo da temperatura. Revista Brasileira de Fruticultura, Jaboticabal, v.23, n.2, p. 270273,2001.

ATKINSON, R.G.; BOLITHO, K.M.; WRIGHT, M.A.; ITURRIAGAGOITIA-BUENO, T.; REID, S. J.; ROSS, G.S. Apple ACC-oxidase and polygalacturonase: ripening specific gene expression and promoter analysis in transgenic tomato. Plant Molecular Biology, Dordrecht, v.38, p.449-460, 1998.

AYUB, R.; MONIQUE, G.; BEN AMOR, M.; GILLOT, L.; ROUSTAN, J.P.; LACTCHE, A.; BOUZAYEN, M.; PECH, J.C. Expression of ACC oxidase anti-sense gene inhibits ripening of cantaloupe melon fruits. Nature Biotecnology, New York, v.14, p.862-866, 1996.

FAN, X.; BLANKENSHIP, S.M.; MATTHEIS, J.P. 1-Methylcyclopropene inhibits apple ripening. Journal of the American Society for Horticultural Science, Alexandria, v.124, n.6, p.690-695, 1999.

GOLDING, J.B., SHEARER, D., WYLLIE, S.G., McGLASSON, W.B. Application of 1-MCP and propylene to identify ethylene-dependent ripening processes in mature banana fruit. Postharvest Biology and Technology, Amsterdam, v.14, p.87-98, 1998.
LELIÈVRE, J.M.; LATCHÉ, A.; JONES, B.; BOUZAYYEN, M.; PECH, J.C. Ethylene and fruit ripening. Physiologia Plantarum, Copenhagen, v.101, p.727-739, 1997.

MIR, A.N.; CURELL, E.; KHAN, N.; WHITAKER, M.; BEAUDRY, R.M. Harvest maturity, storage temperature, and 1-MCP application frequency alter firmness retention and chlorophyll fluorescence of 'Redchief Delicious' apples. Journal of the American Society for Horticultural Science, Alexandria. v.126, n.5, p.618-624, 2001.

$\mathrm{PECH}$, J. C. Unravelling the mechanisms of fruit ripening and development of sensory quality thought the manipulation of ethylene biosynthesis in melon. In: NATO ADVANCED RESEARCH WORKSHOP ON BIOLOGY AND BIOTECHNOLOGY OF THE PLANT HORMONE ETHYLENE, 2002, Murcia. Anais...

PORAT, R.; WEISS, B.; COHEN, L.; DAUS, A.; GOREN, R.; DROBY, S. Effects of ethylene and 1-methylcyclopropene on the postharvest qualities of 'Shamouti' oranges. Postharvest Biology and Technology, Amsterdam, v.15, p.155-163, 1999.

SISLER, E.C.; DUPILLE, E.; SEREK, M. Effect of 1-methylcyclopropene and methylenecyclopropane on ethylene binding and ethylene action on cut carnations. Plant Growth Regulation, Dordrescht, v.8, p.79-86, 1996.

SISLER, E.C.; SEREK, M. Inhibitors of ethylene responses in plants at the receptor level: Recent developments. Physiologia Plantarum, Copenhagen, v.100, p.577-582, 1997.

WATKINS, C.B.; NOCK, J.F.; WHITAKER, D.B. Responses of early, mid and late season apple cultivars to postharvest application of 1metylcyclopropene (1-MCP) under air and controlled atmosphere storage conditions. Postharvest Biology and Technology, Amsterdam, n.19, p.17-32, 2000.

WATKINS, B. C. Possible Implications of 1-Metylcyclopropene Registration for use on horticultural products. In: NATO ADVANCED RESEARCH WORKSHOP ON BIOLOGY AND BIOTECHNOLOGY OF THEPLANTHORMONEETHYLENE, 2002, Murcia. Anais...

ZANELLA, A. Controllo del riscaldo e miglioramento della qualità delle mele Granny Smith mediante 1-MCP applicato in post-raccolta. Rivista di Frutticoltura e di Ortofloricoltura, Bologna, v.63, p.67$72,2001$. 